\title{
INCIDENCE \& CAUSES OF NEONATAL HYPOGLYCEMIA AFTER CESAREAN SECTION IN A RURAL SETUP OF WEST BENGAL
}

Rudradev Meyur ${ }^{1}$, Anirban Sadhu², Abhijit Bhakta3 ${ }^{3}$, Maitreyi Bandyopadhyay4, Banani Kundu 5 , Srimanta Bhaumik ${ }^{6}$, Loknath Ghoshal ${ }^{7}$, Bhaskar Pal ${ }^{8}$

\section{HOW TO CITE THIS ARTICLE:}

Rudradev Meyur, Anirban Sadhu, Abhijit Bhakta, Maitreyi Bandyopadhyay, Banani Kundu, Srimanta Bhaumik, Loknath Ghoshal, Bhaskar Pal. "Incidence \& Causes of Neonatal Hypoglycemia after Cesarean Section in a Rural Setup of West Bengal". Journal of Evolution of Medical and Dental Sciences 2014; Vol. 3, Issue 05, February 03; Page: 1191-1194, DOI: $10.14260 /$ jemds/2014/1967

BACKGROUND: Neonatal hypoglycaemia a major cause of morbidity and mortality may lead to permanent brain damage. This is more common in babies delivered by Caesarean Section. AIMS: A clinico-statistical study was performed among newborns delivered by Caesarean Section for a period of 1 year to find out: 1 . The incidence of neonatal hypoglycemia at $48 \mathrm{hrs}$ of birth. 2 . Risk factors of neonatal hypoglycemia in case of cesarean section. 3. Incidence of neonatal hypoglycemia in newborns of mothers with obstetrical risks (dribbling, PET, \& prolonged labour). 4. Incidence of hypoglycemia among low birth weight babies. SETTINGS AND DESIGN: A cross-sectional observational study was conducted based on deliveries by Caesarean Section over a period of 1 year. METHODS AND MATERIAL: Screening was done by GOD-POD (Glucose Oxidase-Peroxidase) method from new born blood (venous) at $48 \mathrm{hrs}$ of life. We considered neonatal hypoglycaemia as blood glucose concentration $<50 \mathrm{mg} / \mathrm{dl}$. Gestational age was calculated from LMP (Last Menstrual Period). Additionally low birth weight babies were also considered for the study. STATISTICAL ANALYSIS: The number of newborns suffering from hypoglycaemia in each of the above groups were determined from the blood test and their incidences were calculated with respect to the total number of newborns (221) selected for the study. RESULTS: The overall incidence of neonatal hypoglycemia at $48 \mathrm{hrs}$ was 16.3\%.Those suffering from both preterm and dribbling the incidence of neonatal hypoglycemia was $100 \%$. Other cases with risk factors had high incidence rates. CONCLUSION: The study reveals the importance of the risk factors for neonatal hypoglycaemia. All high risk cases had high incidence of neonatal hypoglycaemia. We should always be vigilant about those to prevent neonatal morbidity and mortality.

KEYWORDS: Caesarean Section, Hypoglycaemia, Neonate, risk factors

INTRODUCTION: Neonatal hypoglycemia is one of the major causes of neonatal morbidity and mortality. It is accepted that persistent early and prolonged hypoglycemia results in brain damage and mental retardation. Delay in treatment may lead to significant neurological consequences such as permanent brain damage or even both ${ }^{1}$. Blood glucose levels were significantly lower in infants delivered by Caesarean Section during 36-72 hrs. of life compared to infants born vaginally (52.3 \pm 9.1 vs. $69.2 \pm 10.9 \mathrm{mg} / \mathrm{dl} \mathrm{p}<0.01)^{2}$. In this study we evaluated the incidence of neonatal hypoglycemia at $48 \mathrm{hrs}$. of delivery after caesarean section in a rural set up of West Bengal. We considered neonatal hypoglycemia as whole blood glucose concentration of $<50 \mathrm{mg} / \mathrm{dl}^{3,4}$.

METHODS AND MATERIALS: 221 newborns delivered by Caesarean Section were considered for the study. Out of these 61 were born to mothers with obstetrical risks: dribbling due to rupture of membrane, PET (Pre-Eclamptic Toxemia), post CS (Caesarean Section) pregnancy, preterm with dribbling \& prolonged labor. Screening was done by GOD-POD (Glucose Oxidase-Peroxidase) method from new born blood (venous) at $48 \mathrm{hrs}$. of life. We considered neonatal hypoglycemia as blood 
glucose concentration $<50 \mathrm{mg} / \mathrm{dl} .{ }^{4}$ Gestational age was calculated from LMP (Last Menstrual Period). Additionally low birth weight babies were also considered for the study. The number of newborns suffering from hypoglycemia in each of the above groups were determined from the blood test and their incidences were calculated with respect to the total number of newborns (221) selected for the study.

\section{RESULTS:}

1. The overall incidence of neonatal hypoglycemia at $48 \mathrm{hrs}$. was $16.3 \%$.

2. In case of dribbling the incidence of neonatal hypoglycemia was $82.33 \%$.

3. In case of PET the incidence of neonatal hypoglycemia after was $69.23 \%$.

4. In case of non-progress of labor the incidence of neonatal hypoglycemia was $42.85 \%$

5. Incidence was $14.28 \%$ for post-CS pregnancies in active labor.

6. Those suffering from both preterm and dribbling the incidence of neonatal hypoglycemia was $100 \%$.

7. Among the low birth weight babies incidence of neonatal hypoglycemia was $52.77 \%$.

DISCUSSION: Hypoglycemia is a common abnormality in newborns. The major long term sequelae of prolonged hypoglycemia are mental retardation, recurrent seizure activity or both 5 . In neonates there is not always an obvious correlation between glucose concentration and classic clinical manifestation of hypoglycemia. The absence of symptoms does not always indicate that the glucose concentration is normal and that it has not fallen to less than some optimal level for maintaining brain metabolism ${ }^{5}$.

Prognosis of these newborns with hypoglycemia depends on how promptly and efficiently hypoglycemia is managed. Thus emphasis is on prevention and early detection along with treatment of asymptomatic as well as symptomatic hypoglycemia. There is no study that looks specifically into the optimal timing for glucose screening. An infant is usually born with a blood glucose concentration of $60 \%-70 \%$ of the maternal level. It falls during the first $24 \mathrm{hrs}$. This is followed by a transient rise in blood glucose level during next $24 \mathrm{hrs}$. and dangerously low levels may be encountered at the age of 3 to 4 days before stability is achieved 6 . This is the rationale for collecting blood samples at 48 hours in the present study.

Routine monitoring of blood glucose to prevent brain damage is done in the following high risk situation:

1. Small for date babies smaller of the discordant twin

2. Infant of diabetic mother or those with birth weight of above $90^{\text {th }}$ percentile for the period of gestation.

3. Preterm infant $<35$ weeks gestation.

4. Rhesus hemolytic disease of new born.

5. Babies with symptoms suggestive of hypoglycemia.

6. Babies with prolong hypoxia, hypothermia, polycythemia, septicemia, cardiac failure and suspected metabolic disorder.

7. Infants born to mothers receiving therapy with terbutalin, propranolol and oral hypoglycemic agent.

8. Infants on IV fluid or total parental nutrition. 
Routine monitoring of blood glucose in above high risk situations is recommended 2 hours after birth and there after 4-6 hrly for first $48 \mathrm{hrs}$. of life prior to feeding6.

No study has been found relating the obstetrical risk factors associated with neonatal hypoglycemia after Caesarean delivery, in a Medline search that included the key word "neonatal hypoglycemia" and "Caesarean Section". Incidence of neonatal hypoglycemia in universal literature is 20.6\% 7.In this study we examined 221 mothers who had gone for Caesarean Section for different indications. Blood samples were collected from all babies at 48 hrs. 36 babies were suffering from hypoglycemia - of these 15 were delivered by Caesarean Section due to dribbling, 9 due to PET, 3 due to non-progress of labor, 3 due to APH, 2 due to post CS in active labor and 4 due to other causes. Number of mothers delivered by Caesarean Section due to dribbling were 18, due to PET were 13, due to APH were 9, due to non-progress of labor were7, and due to post CS in active labor were 14 (Table 1).

In our study the incidence of hypoglycemia in newborns after caesarean delivery at 48 hrs. was $16.3 \%$ and high risk factors were dribbling, PET, non-progress of labor, APH and low birth weight babies. Of these 36 babies suffering from hypoglycemia, 19 were low birth weight $(<2.5 \mathrm{~kg})$. The outcome of study may vary on maternal nutritional status, hour of fasting before cesarean section, amount of hydration fluid before surgery (as in all cases ringer lactate has been used), and frequency of breast feeding etc. Not only that the incidence may be higher if samples are collected at different hours 1, 3, 24, 48, 72hrs etc.

ACKNOWLEDGMENTS: The authors would like to express their sincere gratitude to all faculty members and non-teaching staff of our institute for their whole-hearted support for this project.

\section{REFERENCES:}

1. Najati $\mathrm{N}$ and Saboktakin L. Prevalence and Underlying etiologies of Neonatal hypoglycemia. Pakistan Journal of Biological Sciences 2010; 13:753-6.

2. Yoshitada Yamauchi. Hypoglycemia in healthy, full-term breast-fed neonates during the early days of life: Preliminary observations. (Abstract) The American Pediatric Society and The Society for Pediatric Research 1996; 39:254.

3. Mark A Sperling. Hypoglycemia in Nelson Text Book of Pediatrics, Elsevier, A Division of Reed Elsevier India Pvt Ltd New Delhi, 19/e, Chapter 86, 2012, 517.

4. Richard E Wilker. Hypoglycemia and Hyperglycemia, Manual of Neonatal Care, Wolters Kluwer (India) Pvt Ltd New Delhi, 7/e, Chapter 24, 2011;285.

5. Mark A Sperling, Hypoglycemia, Nelson Text Book of Pediatrics, Elsevier, A Division of Reed Elsevier India Pvt Ltd New Delhi, 19/e, Chapter 86, 2012, 517.

6. Meherban Singh. Care of New Born Sagar Publication New Delhi, 7/e, Chapter 24, 2010; 373-4.

7. Burdan D R, Botiu V, Teodorescu D. Neonatal Hypoglycemia - The Incidence Of The Risk Factors In Salvator Vuia Obstetrics-Gynecology Hospital, Arad. Timisoara Medical Journal 2009; 59:78. 


\begin{tabular}{|c|l|c|c|}
\hline Sl. No & Indication for CS & $\begin{array}{c}\text { No. of mothers } \\
\text { operated upon }\end{array}$ & $\begin{array}{c}\text { No. of newborns } \\
\text { with hypoglycemia }\end{array}$ \\
\hline 01 & Dribbling & 18 & 15 \\
\hline 02 & PET & 13 & 09 \\
\hline 03 & Non progress of labor & 9 & 03 \\
\hline 04 & APH & 7 & 03 \\
\hline 05 & Post CS & 14 & 02 \\
\hline
\end{tabular}

TABLE 1: Distribution of mothers and newborns considered for the study

\section{AUTHORS:}

1. Rudradev Meyur

2. Anirban Sadhu

3. Abhijit Bhakta

4. Maitreyi Bandyopadhyay

5. Banani Kundu

6. Srimanta Bhaumik

7. Loknath Ghoshal

8. Bhaskar Pal

\section{PARTICULARS OF CONTRIBUTORS:}

1. Associate Professor, Department of Anatomy, R.G. Kar Medical College, 1, Kshudiram Bose Sarani, Kolkata, West Bengal, India.

2. Assistant Professor, Department of Anatomy, R.G. Kar Medical College, 1, Kshudiram Bose Sarani, Kolkata, West Bengal, India.

3. Associate Professor, Department of Anatomy, NRS Medical College, 138, AJC Bose Road, Kolkata - 700014, West Bengal, India.

4. Associate Professor, Department of Microbiology, R.G. Kar Medical College, 1, Kshudiram Bose Sarani, Kolkata, West Bengal, India.
5. Assistant Professor, Department of Anatomy, R.G. Kar Medical College, 1, Kshudiram Bose Sarani, Kolkata, West Bengal, India.

6. Consultant Paediatrician, Department of Anatomy, Sanjiban Nursing Home, Tarakeswar, West Bengal, India.

7. Assistant Professor, Department of Dermatology, NRS Medical College, 138, AJC Bose Road, Kolkata, West Bengal, India.

8. Professor, Department of Anatomy, R.G. Kar Medical College, 1, Kshudiram Bose Sarani, Kolkata, West Bengal, India.

\section{NAME ADDRESS EMAIL ID OF THE CORRESPONDING AUTHOR:}

Dr. Anirban Sadhu, 2, Mahakalitala Lane,

PO: Bansberia, Dist: Hooghly, PIN: 712502, West Bengal, India.

E-mail: anir_sd@rediffmail.com

Date of Submission: 26/12/2013.

Date of Peer Review: 27/12/2013.

Date of Acceptance: 23/01/2014.

Date of Publishing: 29/01/2014. 